\title{
Review of Biosynthesis Silver Nanoparticles by Microbiology
}

\author{
Dr. Hawraa Natiq Kabroot al-Fatlawy ${ }^{1 *}$, Khwla Abd Al Kadhem Rahi ${ }^{2}$, Diaa Sarhan Abd Al Zahra ${ }^{3}$, \\ Samara Rahem Hudud ${ }^{4}$, Hussein Ali Hussein ${ }^{5}$, Ahmed Hazem Mohammed ${ }^{6}$ \\ 1,2,3,4,5,6 Department Medical Laboratories Techniques, Al-Toosi University College, Iraq \\ *e-mail: dr.hawraank9@altoosi.edu.iq
}

\begin{abstract}
Nanotechnology is a multidisciplinary field that evolved within the past few decades and played a substantial role in the environment, industry, agriculture, and pharmacology. Nanoparticles are generally classified based on their dimensionality, morphology, composition, uniformity, and agglomeration. The shape, and morphology of nanoparticles play an essential role in their functionality and toxic effect on the environment and humans. In this review, we discuss the biosynthesis of nanoparticles from microbes. For the biological synthesis of nanoparticles, microbes have been exploited all over the globe. Microbes like bacteria, fungi, and yeasts are mostly preferred for nanoparticles (NPS) synthesis because of their fast growth rate, easy cultivation, and their ability to grow at ambient conditions of temperature, $p H$, and pressure. Applications of Nanoparticles is a field of research with tremendous prospects for the improvement of the diagnosis and treatment of human diseases. Microbial nanoparticles are found to have vigorous antibacterial activities. The nanoparticles' efficiency is probably due to their larger surface area for enhanced interaction with the micro-organisms. Nanoparticles adhere to the cell membrane and further penetrate inside by interacting with DNA, thereby interfering with the replication process or may attack the respiratory chain of pathogens. A similar bactericidal mechanism of silver nanoparticles obtained from endophytic bacterium Bacillus cereus was observed against pathogenic bacteria like Salmonella typhi, Escherichia coli, Klebsiella pneumonia, Staphylococcus aureus, and Pseudomonas aeruginosa.
\end{abstract}

Keywords: Silver Nanoparticles 1, Microbiology 2, antibacterial activities 3

\author{
Article Information \\ Received: November 20, 2020; Online: December 4, 2020
}

\section{INTRODUCTION}

Nanoparticles are particles having one or more dimensions of $100 \mathrm{~nm}$ or less have attracted significant attention due to their unusual and fascinating properties and applications advantageous over their bulk counterparts (Daniel and Astruc,.2004.; Kato,.2011). There are many physical, chemical, biological, and hybrid methods available to synthesize different types of nanoparticles ( Liu et al.,2011). Although physical and chemical methods are more prevalent in nanoparticle synthesis, toxic chemicals limit their biomedical applications in clinical fields. Therefore, the development of reliable, non-toxic, and eco-friendly methods for synthesizing nanoparticles is of utmost importance to expand their biomedical applications (Kato,.2011). Nanoparticles are biosynthesized when the micro-organisms grab target ions from their environment and then turn the metal ions into the element metal through enzymes generated by the cell activities. It can be classified into intracellular and extracellular synthesis according to the location where nanoparticles are formed (Mann,2001). The intracellular method consists of transporting ions into the microbial cell to form nanoparticles in enzymes' presence. The extracellular 
synthesis of nanoparticles involves trapping the metal ions on the cells' surface and reducing ions in enzymes' presence (Zhang et al.; 2011). The biosynthesized nanoparticles have been used in various applications, including drug carriers for targeted delivery, cancer treatment, gene therapy and DNA analysis, antibacterial agents, biosensors, enhancing reaction rates, and separation science and magnetic resonance imaging (MRI).

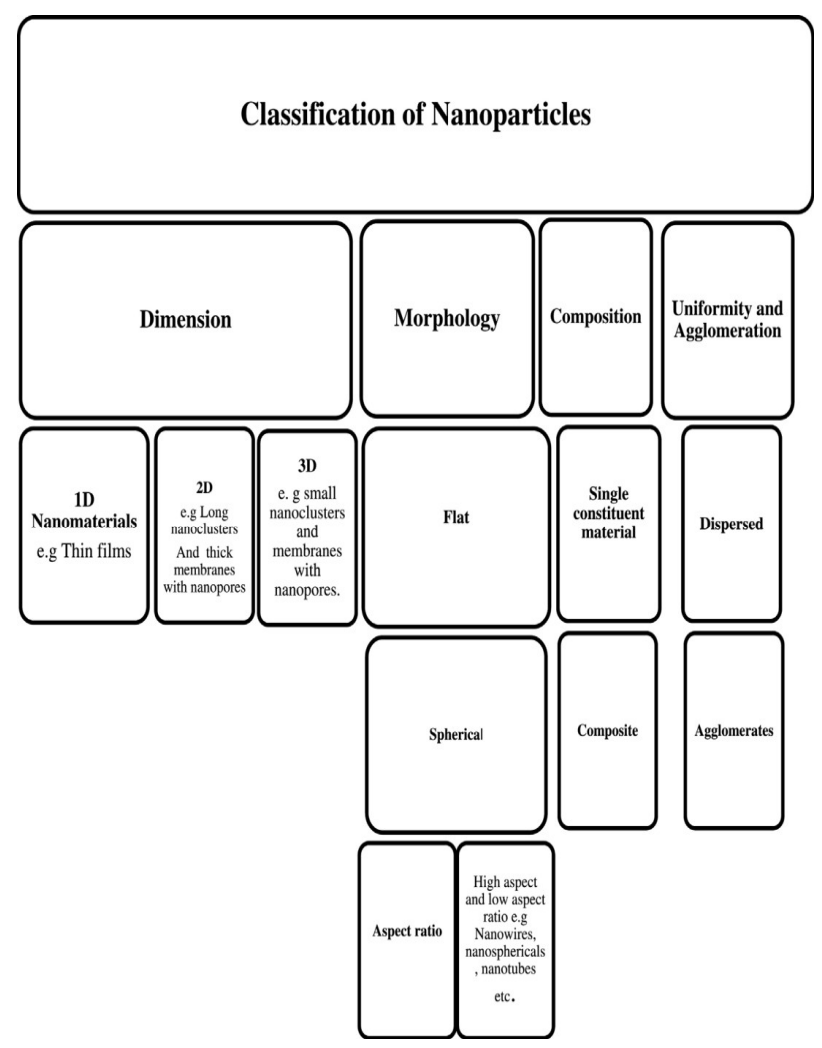

Fig. 1. Classification of nanoparticles

(Fariq et al., 2017).

\section{Biological Synthesis of Nanoparticles by Micro-organisms}

Biological entities and inorganic materials have been in constant touch with each other ever since the inception of life on the earth. Due to this regular interaction, life could sustain this planet with a well-organized mineral deposit (Xiangqian et al., 2011). Recently scientists have become more and more interested in the interaction between inorganic molecules and biological species. Studies have found that many micro-organisms can produce inorganic nanoparticles through either intracellular or extracellular routes. The production of various nanoparticles via biological methods following the categories of metallic nanoparticles including gold, silver, alloy, and other metal nanoparticles, oxide nanoparticles are consisting of magnetic and nonmagnetic oxide nanoparticles, sulfide nanoparticles, and other miscellaneous nanoparticles (Xiangqian et al., 2011).

\section{SilverNanoparticles}

Like their bulk counterpart, silver nanoparticles show effective antimicrobial activity against Gram-positive and Gramnegative bacteria, including highly multiresistant strains such as methicillinresistant Staphylococcus aureus (Panáček et al.,.2006). The secrets discovered from nature have led to the development of biomimetic approaches to the growth of advanced nanomaterials. Recently, scientists have made efforts to use micro-organisms as possible ecofriendly nano factories to synthesize silver nanoparticles. Various microbes are known to reduce the $\mathrm{Ag}+$ ions to form silver nanoparticles, mostly spherical particles (Fayaz et al., 2010). Klaus and coworkers have shown that the bacterium Pseudomonas stutzeri isolated from a silver mine, when placed in a concentrated aqueous solution of silver nitrate, played a significant role in the reduction of the $\mathrm{Ag}+$ ions and the formation of silver nanoparticles (AgNPs) of well-defined size and distinct topography within the periplasmic space of the bacteria (Klaus et al.,.1999). AgNPs were synthesized in the form of a film or produced in solution or accumulated on its cell surface when fungi, Verticillium, Fusarium oxysporum, or Aspergillus flavus were employed (Jain et al., 2011).

\section{Mechanisms of Nanoparticle Formation by Micro-organisms}

Different micro-organisms have different mechanisms for forming nanoparticles. However, nanoparticles are usually formed following this way as metal ions are first trapped on the microbial cells' surface or inside. The trapped metal ions are then reduced to nanoparticles in enzymes' presence (Benzerara et al., 2010). In general, micro-organisms impact mineral formation in two distinct ways. They can modify the composition of the solution to become supersaturated or more supersaturated than it previously was 
concerning a specific phase. A second means by which micro-organisms can impact mineral formation is through the production of organic polymers, which can impact nucleation by favoring (or inhibiting) the stabilization of the very first mineral seeds (Benzerara et al., 2010). The exact mechanism for the intracellular formation of silver nanoparticles by microorganisms. The silver ions were first trapped on the fungal cells' surface via electrostatic interaction between the ions and negatively charged cell wall from the carboxylate groups in the enzymes (Sneha et al., 2010). The formation of fatty metallic nanoparticles can be attributed to metallophilic micro-organisms developed by genetic and proteomic responses to toxic environments (Reith et al., 2007). Heavy metal ions, for example, $\mathrm{Hg} 2+, \mathrm{Cd} 2+, \mathrm{Ag}+, \mathrm{Co} 2+$, $\mathrm{Cu} 2+, \mathrm{Ni} 2+, \mathrm{Pb} 2+$, and $\mathrm{Zn} 2+$, cause toxic effects on the survival of micro-organisms. Micro-organisms have developed genetic and proteomic responses to regulate metal homeostasis (Nies, 1999) strictly.

\section{Applications of Nanoparticles.}

Nanomedicine is a burgeoning field of research with tremendous prospects for improving the diagnosis and treatment of human diseases (Fadeel et al.,.2010). Dispersed nanoparticles are usually employed in Nano biomedicine as fluorescent biological labels (Chan and Nie,.2016). Drug and gene delivery agents (Cui et al., 2007). Also, in applications such as bio-detection of pathogens, tissue engineering, tumor destruction via heating (hyperthermia), MRI contrast enhancement, and phagokinetic studies (Ma et al., 2003; Alanazi et al., 2010).

\section{Drug Delivery.}

Delivering the drugs precisely and safely to their target sites at the right time to have a controlled release and achieve the maximum therapeutic effect is a critical issue in the design and development of novel drug delivery systems. Targeted Nanocarriers must navigate through blood-tissue barriers to reach target cells. They must enter target cells to contact cytoplasmic targets via specific endocytotic and transcytotic transport mechanisms across cellular barriers (Fadeel et al.,.2010). Because of their small size, nanoparticle drug carriers can bypass the blood-brain barrier and the skin's tight epithelial junctions that typically impede drug delivery to the desired target site. Secondly, due to their high surface area to volume ratio, Nanocarriers show improved pharmacokinetics and biodistribution of therapeutic agents and minimized toxicity by their preferential accumulation at the target site (Vaidyanathan et al., 2009). Silver nanoparticles have been widely used as a novel therapeutic agent extending their use as antibacterial, antifungal, antiviral, and anti-inflammatory agents. Kalishwaralal et al.(2009) found that silver nanoparticles produced by Bacillus licheniformis have anti-angiogenic potential (Kalishwaralal et al.,2009).

\section{Antibacterial Agent.}

The prevalence and increase of microorganisms resistant to multiple antibiotics, silver-based antiseptics have been emphasized in recent years. Silver nanoparticles were biosynthesized using fungus (Fayaz et al., 2010). It was observed that the aqueous silver $(\mathrm{Ag}+)$ ions, when exposed to a filtrate of $T$. viride, were reduced in solution, thereby leading to the formation of exceedingly stable AgNPs with the size of $5-40 \mathrm{~nm}$. The nanoparticles were also evaluated for their increased antimicrobial activities with various antibiotics against Gram-positive and Gram-negative bacteria. The antibacterial activities of ampicillin, kanamycin, erythromycin, and chloramphenicol were increased in the presence of AgNPs against test strains. The highest enhancing effect was observed for ampicillin against test strains. The result showed that the combination of antibiotics with AgNPs has better antimicrobial effects and provided helpful insight into new antimicrobial agents' development. Durán and coworkers showed that extracellularly produced silver nanoparticles using Fusarium oxysporum could be incorporated into textile fabrics to prevent or minimize infection with pathogenic bacteria such as Staphylococcus aureus ( Durán et al.,2007).

\section{Nanoparticles in diagnostics}

Prevalence of infectious diseases is one of the significant causes of morbidity and mortality in developing countries. Though infectious 
diseases initiate in a confined place, they may spread quickly from one region to another and become a global pandemic. Innovative technologies of relevant diagnostics are required to detect diseases (Hauck et al., 2010) rapidly. Traditional disease detection and diagnosis methods are culturing micro-organisms, microscopy, biochemical tests, immunoassays, and molecular diagnostics. Nevertheless, these methods are tedious, time-consuming, and laborious. Nanomaterials offer rapid, specific, accurate, easy-to-use, and ultrasensitive diagnostic tools for pathogen detection. Metallic nanoparticles, fluorescent nanoparticles (quantum dots and dye-loaded nanoparticles), and magnetic nanoparticles have been effectively exploited to image, track, and identify numerous pathogens (Tallury et al., 2010). However, little is known about the role of biosynthesized nanomaterials in diagnostics.

\section{CONCLUSION}

This review summarizes the microbial route for the synthesis of nanoparticles and their potential applications in health and medicine: There have been tremendous developments in the field of

\section{REFERENCES}

Alanazi, F.K.; Radwan, A. and Alsarra, I. A (2010)."Biopharmaceutical applications of nanogold," Saudi Pharmaceutical Journal, vol. 18, no. 4, pp.179-193.

Benzerara, K.; Miot, J.; Morin, G.; Ona Nguema, G.; Skouri-Panet, F. And Férard, C. (2010)."Significance, mechanisms and environmental implications of microbial biomineralization," Comptes Rendus Geoscience, vol. 343, no. 2-3, pp. 160-167.

Chan, W.C.W, and Nie, S.S.(2016). Quantum dot bioconjugates for ultrasensitive nonisotopic detection. Science, vol. 281, no. 5385, pp. 2016-2018.

Cui, D.; Tian, F.; Coyer, S. R. et al.(2007). Effects of antisense-my conjugated single-walled carbon nanotubes on HL-60 cells. Journal of Nanoscience and Nanotechnology, vol. 7, no. 4-5, pp. 1639-1646.

Daniel, M. C, and Astruc, D.(2004). "Gold nanoparticles: assembly, supramolecular chemistry, quantum-size-related properties, and applications toward biology, catalysis, and microorganism-produced nanoparticles and their applications over the last decade. The work is needed to improve the synthesis efficiency and the control of particle size and morphology. It is known that the synthesis of nanoparticles using micro-organisms is a relatively slow process (several hours and even a few days) compared to physical and chemical approaches. Reduction of synthesis time will make this biosynthesis route much more attractive. Particle size and monodispersity are two critical issues in the evaluation of nanoparticle synthesis.

\section{RECOMMENDATIONS:}

According to the previous studies, we funding to use the Biosynthesis Nanoparticles in medicine and pharma such as silver nanoparticles may represent a new chance in the medical fields because they can act as alternative antibiotics that affect different bacterial mechanisms such as virulence and resistance. We explored the potential of $\mathrm{AgNO} 3$ to inhibit the growth of different pathogenic bacteria, including multidrug-resistant bacteria.

nanotechnology," Chemical Reviews, vol. 104, no. 1, pp. 293-346.

Durán, N.; Marcato, P. D.; De Souza, G. I. H .; Alves, O. L, and Esposito, E. (2007). Antibacterial effect of silver nanoparticles produced by fungal process on textile fabrics and their effluent treatment," Journal of Biomedical Nanotechnology, vol. 3, no. 2, pp. 203-208.

Fadeel, B., and Garcia-Bennett, A. E.( 2010). "Better safe than sorry: understanding the toxicological properties of inorganic nanoparticles manufactured for biomedical applications," Advanced Drug Delivery Reviews, vol. 62, no. 3, pp. 362-374.

Fayaz, A.M.; Balaji, K.; Girilal, M.; Yadav, R.; Kalaichelvan, P.T., and R.Venketesan, R.(2010)."Biogenic synthesis of silver nanoparticles and their synergistic effect with antibiotics: a study against gram-positive and gram-negative bacteria," Nanomedicine: Nanotechnology, Biology, and Medicine, vol. 6, no. 1, pp. e103-e109.

Hauck, T.S., Giri, S., Gao, Y., Chan, W.C.(2010). Nanotechnology diagnostics for infectious diseases prevalent in developing countries. Adv. Drug Deliv. Rev. 62, 438-448. 
doi:http://dx.doi.org/10.1016/j.addr.2009.11. 015 .

Jain, N. Bhargava, A.; Majumdar, S.; Tarafdar, J. $\mathrm{C}$ and Panwar, J. (2011). Extracellular biosynthesis and characterization of silver nanoparticles using Aspergillus flavus NJP08: a mechanism perspective.Nanoscale, vol.3, no. 2, pp. 635-641.

Kalishwaralal, K.; Banumathi, E.; Pandian S.R.K and et al.(2009). Silver nanoparticles inhibit VEGF induced cell proliferation and migration in bovine retinal endothelial cells. Colloids and Surfaces B, vol. 73, no. 1, pp. 51-57.

Kato, H. (2011). "In vitro assays: tracking nanoparticles inside cells," Nature Nanotechnology, vol. 6, no. 3, pp. 139-140.

Klaus, T.; Joerger, R.; Olsson, E, and Granqvist, C.G.(2009). "Silver-based crystalline nanoparticles, microbially fabricated," Proceedings of the National Academy of Sciences of the United States of America, vol. 96, no. 24, pp. 13611-13614.

Liu, J.; Qiao, S.Z.; Hu, Q. H, and Lu, G.Q (2011). "Magnetic nanocomposites with mesoporous structures: synthesis and applications," Small, vol. 7, no. 4, pp. 425-443.

Ma, J.; Wong, H.; Kong, L. B and Peng, K. W.(2003).Biomimetic processing of nanocrystallite bioactive apatite coating on titanium," Nanotechnology, vol. 14, no. 6, pp. 619-623.

Mann, S.(2001). Biomineralization: Principles and Concepts in Bioinorganic Materials Chemistry, Oxford University Press, Oxford, UK.
Nies, D. H. (1999). Microbial heavy-metal resistance. Applied Microbiology and Biotechnology, vol. 51, no. 6, pp. 730-750, 1999.

Panáček, A.; Kvítek L. .; Prucek, R. and et al.,(2006). "Silver colloid nanoparticles: synthesis, characterization, and their antibacterial activity," The Journal of Physical Chemistry B, vol. 110, no. 33, pp. 16248-16253.

Reith, F.; Lengke, M. F.; Falconer, D.; Craw, D. and Southam, G. (2007). The geomicrobiology of gold. The ISME Journal, vol. 1, no. 7, pp. 567-584.

Sneha, K.; Sathishkumar, M.; Mao, J.; Kwak, I. S. and Yun, Y. S. (2010). Corynebacterium glutamicum-mediated crystallization of silver ions through sorption and reduction processes, Chemical Engineering Journal, vol. 162, no. 3, pp. 989-996.

Tallury, P., Malhotra, A., Byrne, L.M., Santra, S.( 2010). Nanobioimaging and sensing of infectious diseases. Adv. Drug Deliv. Rev. 62, 424-437. doi:http://dx.doi.org/10.1016/ j.addr.2009.11.014.

Vaidyanathan R.; Kalishwaralal, K.; Gopalram, S and Gurunathan, S. (2009). Nanosilver-the burgeoning therapeutic molecule and its green synthesis. Biotechnology Advances, vol. 27, no. 6, pp.924-937.

Zhang, X.; Yan, S.; Tyagi, R.D and Surampalli, R.Y.(2011). "Synthesis of nanoparticles by micro-organisms and their application in enhancing microbiological reaction rates," Chemosphere, vol. 82, no. 4, pp. 489-494. 